\title{
Whether green technology innovation is conducive to haze emission reduction: Empirical evidence from China
}

\section{Ming Yi}

China University of Geosciences

\section{Ying Lu ( $\sim 1053536816 @ q q . c o m)$}

China University of Geosciences https://orcid.org/0000-0002-6991-6020

\section{Le Wen}

Energy Center of Auckland University

\section{Ying Luo}

Huazhong University of Science and Technology

\section{Shujing Xu}

China University of Geosciences

\section{Tian Zhang}

Tulane University

\section{Research Article}

Keywords: Green technology innovation, Haze pollution control, Spatial panel

Posted Date: June 9th, 2021

DOI: https://doi.org/10.21203/rs.3.rs-172715/v1

License: (1) This work is licensed under a Creative Commons Attribution 4.0 International License. Read Full License

Version of Record: A version of this preprint was published at Environmental Science and Pollution Research on September 24th, 2021. See the published version at https://doi.org/10.1007/s11356-02116467-w. 


\title{
1 Whether Green Technology Innovation is
}

2 Conducive to Haze Emission Reduction: Empirical

3 Evidence from China

4

5

6

\author{
Ming Yia, Ying $\mathrm{Lu}^{\mathrm{a}^{*}}$, Le Wen ${ }^{\mathrm{b}}$, Ying Luo ${ }^{\mathrm{c},}{ }^{,}$, Shujing $\mathrm{Xu}^{\mathrm{a}}$, Tian Zhang ${ }^{\mathrm{d}}$ \\ a School of Economics and Management, China University of Geosciences, Wuhan, Hubei, China \\ b Energy Center of Auckland University, Auckland, New Zealand \\ c School of Economics, Huazhong University of Science and Technology, Wuhan, Hubei, China \\ d Freeman School of Business, Tulane University, New Orleans, Louisiana, America
}

\section{Abstract}

With the acceleration of industrialization, haze pollution has become a severe environmental pollution problem, and green technology innovation is one feasible way to alleviate it. Based on the $\mathrm{PM}_{2.5}$ concentration data of 30 provinces in mainland China from 2011 to 2017, we use a spatial panel model to investigate the spatial characteristics of haze pollution and examine the impact of green technology innovation on it. Results show that haze pollution has spatial correlation and a time lag. Its spatial correlation is associated with geographical distance as well as the compound influence of distance and economic development. Green technology innovation and foreign investment have inhibitory and negative spillover effects on haze pollution. Industrial structure and energy consumption structure play a partial intermediary role between green technology innovation and haze pollution, and the former has a significant negative spillover, while the latter has a positive effect. To reduce haze pollution, China should improve the level of green technology innovation, use foreign investment wisely, and enhance policy support and guidance. It should also promote the rationalization of industrial structure, optimize energy structure and implement energy substitution. Finally, it is crucial that it should strengthen regional collaborative governance and build a multi-agent governance system.

Key words Green technology innovation · Haze pollution control · Spatial panel

\footnotetext{
${ }^{*}$ Corresponding author.

Emil Address: Ming Yi: yiming@cug.edu.cn; Ying Lu: 1053536816@qq.com;

Le Wen: 1.wen@auckland.ac.nz; Ying Luo: hustluoying@hust.edu.cn;

Shujing Xu: missxushujing@163.com; Tian Zhang: tzhang16@tulane.edu
} 
Due to the acceleration of China's industrialization and urbanization, environmental pollution has gradually become an important issue related to national development and people's life, especially haze pollution (Leeuwen and Mohen, 2013). Haze pollution mainly consists of $\mathrm{PM}_{2.5}, \mathrm{PM}_{10}$ and other particles. Among them, $\mathrm{PM}_{2.5}$, which is more subtle, can enter the human lungs and cause more harm to the human body. Therefore, the research on haze pollution mainly focuses on $\mathrm{PM}_{2.5}$. Before 2007, the concentration of $\mathrm{PM}_{2.5}$ emission in China increased rapidly, and since then it has basically stabilized in the range of $36 \mathrm{ug} / \mathrm{m}^{3}-45 \mathrm{ug} / \mathrm{m}^{3}$, but with large annual fluctuations (Fig. 1). Unlike developed countries, the intensity and scope of environmental management in China is still relatively small, making haze pollution present the characteristics of wide range, high frequency, heavy pollution and serious harm. To some extent, the high level of pollutant emission caused by China's rapid economic development is the fundamental reason for the high incidence of haze (Xie et al., 2017), and the unreasonable economic development mode, such as unbalanced industrial structure, unreasonable energy structure, insufficient technological investment and inefficient environmental governance are also important reasons. Solving haze pollution and winning the battle against air pollution is one of the main tasks of China's economic and social development at this stage (Song, Fisher and Kwoh, 2019).

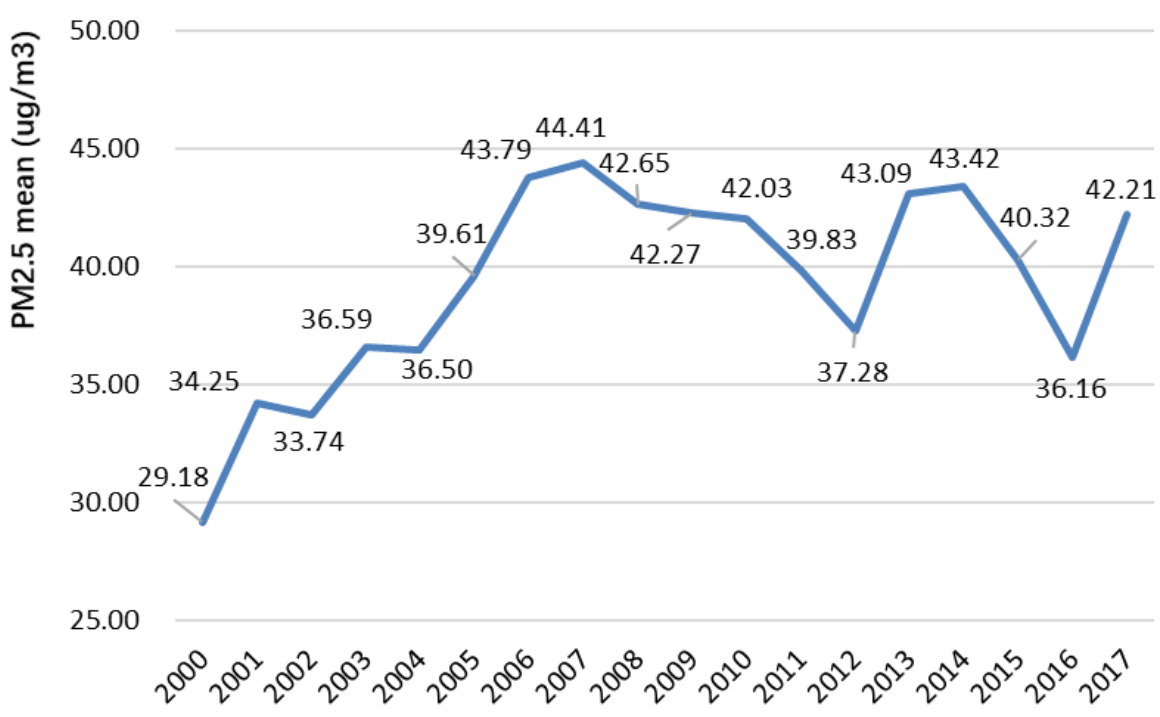

Fig.1 2000-2017 $\mathrm{PM}_{2.5}$ concentration changes in 30 provinces of China (except Tibet)

Green technology innovation taking the realization of green development as the core pursuit, and focusing on providing new products, processes, services and market solutions through innovations, reducing natural resource consumption, reducing ecological environmental damage, improving resource allocation efficiency, which could provide 
power for China to achieve high-quality economic development. Based on the rapid development of green technology innovation and the above environmentally friendly characteristics of green technology innovation, combined with the affirmation of the existing research results on the haze reduction effect of green technology innovation, we focus on the study of green technology innovation on haze reduction to explore whether China's green technology innovation can indeed alleviate haze pollution? The research will enrich China's haze control methods and provide the necessary decision -- making basis for the formulation of haze control policies.
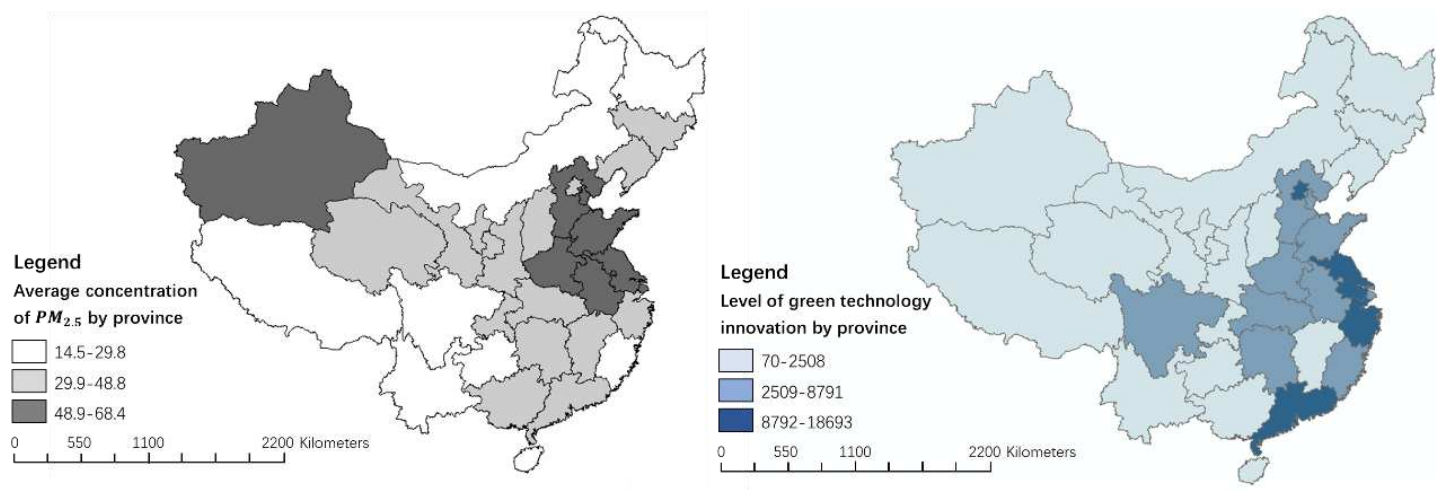

Fig.2 Distribution of average $\mathrm{PM}_{2.5}$ concentrations and green technology innovation levels by province in mainland China in 2017

Fig.2 shows the distribution of $\mathrm{PM}_{2.5}$ and green technology innovation levels by province in mainland China in 2017, from which it can be seen that haze pollution in China is mainly concentrated in eight regions -- Hebei, Tianjin, Shandong, Henan, Anhui, Jiangsu, Shanghai and Xinjiang. And southwest China is less polluted. The regions with higher levels of green technology innovation are Beijing, Jiangsu, Zhejiang and Guangdong. Therefore, the relationship between green technology innovation and haze pollution is not obvious intuitively, and a spatial econometric model needs to be constructed to investigate this issue.

The main contributions of this paper are as follow: First, based on three commonly used spatial measurement models, the spatial correlation effect of haze pollution at the provincial level in China is studied. Second, the haze abatement effect of green technology innovation in China is analyzed based on the weight matrix of geographical distance, economic weight matrix and nested weight matrix of geographical and economic distance. Third, the green technology innovation of each province is measured by the number of green patent applications and $\mathrm{PM}_{2.5}$ refers to haze pollution, which is innovative.

\section{Literature review}

Haze is the result of the interaction between specific climatic conditions and human activities. With the increasing pollution of the atmosphere caused by human activities, 
haze pollution has become a key issue of social concern. In 1995-1999, the international scientific cooperation project "INDOEX" conducted a comprehensive study on atmospheric brown cloud $(\mathrm{ABC})$ and its impact on climate for the first time. It was found that the haze layer over the Indian Ocean, South Asia, Southeast Asia and East Asia has a high content of soot, which mainly comes from the combustion of fossil fuels and biofuels. Based on this experiment, in August 2002, the United Nations Environment Program officially launched the international ABC research project (Ramanathan et al., 2001). The research results of Chun-Chung and Vernon (2006) show that haze pollution will affect China's economic development by influencing the process of urbanization. Chen and Chen (2018) further found that haze pollution greatly reduces the quality of China's economic development and has a particularly significant impact on large cities. Guan et al. (2014) studied the drivers of haze pollution in China by using structural analysis method, and found that capital formation and export production are important causes of haze pollution. It has also been empirically verified that haze pollution has significant spatial characteristics (Ma and Zhang, 2014). Based on the spatial Durbin model, Ma et al. (2016) found that China's coal-based energy consumption structure is an important factor that affects haze pollution.

Green technological innovation is also called ecological technological innovation. It is a technological innovation that promotes the coordinated development of man, nature and society for the purpose of saving resources and energy and protecting the environment. In 1994, Braun and Wield first proposed the concept of "green technology innovation" (Braun and Wield, 1994). And then the concept was introduced to China. Chinese scholars Chen and Wang (1998) first investigated the incentive mechanism of green technology innovation. The "Green Economy Initiative" of the United Nations Environment Program in 2008 and the Copenhagen Conference in 2009 and other related events have made green technology innovation a topic of global concern and the relevant literature has also been enriched. Although China's green technology innovation has made great progress in recent years, it is still in a stage of insufficient development and it is far from completely relying on green technology to develop production (Wang et al., 2019); Luo and Liang (2016) calculated the technological innovation efficiency of China's industrial enterprises through principal component analysis and found that there is a significant regional gap between the eastern, central and western regions, and the gap is still widening.

There are direct and indirect relationships between green technological innovation and haze pollution. Existing studies by domestic and foreign scholars have directly discussed the effects of technological innovation on haze emission reduction and have also studied technological innovation on carbon emissions and energy efficiency. The intermediary factors of the indirect impact of pollution are used to explore the emission reduction effect of green technological innovation. 
In the research on the direct relationship between green technological innovation and haze pollution, Liu (2018a) used the nuclear density method to analyze the dynamic evolution and spatial spillover effects of China's technological innovation and haze pollution. The results showed that technological innovation can not only reduce the province's Haze pollution can also indirectly lead to a decrease in the degree of haze pollution in neighboring provinces through knowledge spillover effects. Liu (2018b) used the spatial Dubin model to analyze the impact of technological innovation on China's PM2.5. The empirical results showed that technological innovation could significantly reduce PM2.5 emissions in the region, neighboring regions, and the world. Yi et al. (2020) considered the heterogeneity of technological progress and analyzed the impact of different technological advances on haze pollution and found that due to the cost reduction effect and income effect, neutral technological progress and technological progress that reduce labor input are beneficial to the haze. However, technological progress that reduces resource input has no significant impact on haze pollution. In addition, due to the energy rebound effect, energy-saving technological progress cannot effectively reduce haze pollution.

In exploring the indirect impact of green technological innovation on haze pollution, scholars often conduct research on the influence of green technological innovation on intermediary factors such as carbon emissions or energy efficiency. Regarding carbon emissions, Honjo (1996) came to the conclusion that green technology innovation reduced carbon emissions through research. Apergis et al. (2013) believed that through green technology innovation, enterprises obtained green technology and produced green products to reduce carbon emissions. Carbon emissions in the production process, thereby reducing environmental pollution. Du et al. (2019) found that in economies with income levels above the critical value, green technology innovation has a significant effect on carbon emissions reduction. Regarding energy efficiency, Garbaccfio et al. (1999) studied the reasons for the sharp decline in China's energy output ratio from 1978 to 1995 and decomposed the reduction in energy consumption into technological changes and various types of structural changes, and found that technological changes were the main reason. The structural changes have increased energy use. Fisher Vanden et al. (2006) also studied the reasons for the increase in energy productivity in China's industrial sector and came to a conclusion similar to Garbaccfio that technological progress and industrial structure optimization are both important factors. Wurlod and Noailly (2018) studied green technology innovation in the industrial sector of OECD countries. Results showed that green patent activities in a specific sector increased by $1 \%$ and energy intensity decreased by $0.03 \%$ and the phenomenon has become more pronounced in recent years. Therefore, existing studies proved that green technological innovation could improve energy efficiency and effectively reduce carbon emissions in production activities. Carbon emission itself has little effect on haze pollution, but its by-products, such as the 
production of particulate matter in combustion, will aggravate haze pollution. In addition, low energy use efficiency is the root cause of air pollution. It may be possible to improve energy efficiency through technological innovation Effectively improve haze pollution, which also shows to a certain extent that green technological innovation has the effect of mitigating and inhibiting environmental pollution.

To sum up, most of the existing literature on green technology innovation and haze pollution researches focus on the indirect impact of green technology innovation on haze pollution and the research literature in this area is relatively abundant. There are relatively few documents that specifically explore the direct relationship between green technological innovation and haze pollution or model the two together to study the haze reduction effect of green technological innovation. Based on the above practical reasons and research background, we take the main "culprit" of haze pollution--PM2.5 and the core indicator of green technology innovation research--the number of green patent applications (Brunnermeier and Cohen, 2003) as the research object. A spatial panel data model is used to empirically test the haze reduction effects of China's inter-provincial green technology innovations to find out the specific effects of green technology innovations on haze pollution, and to find other ways to reduce haze pollution and effectively prevent haze pollution. The research perspective of this paper is relatively innovative, which enriches the empirical research in this field to a certain extent and provides corresponding theoretical reference for China's haze reduction.

\section{Influence mechanism}

The effect of green technological innovation on the prevention and treatment of environmental pollution is self-evident. From the perspective of product life cycle analysis, green technology innovation follows ecological principles and ecological economic laws, and integrates environmental principles at each stage of the innovation process, which not only pays attention to the production cost of the product, but also pays attention to the social and ecological costs of the product to realize the product. The goal is to minimize the total cost of the entire life cycle, which has the characteristics of saving resources and energy and conforming to sustainable development.

The impact of green technological innovation on haze pollution mainly comes from two aspects (Fig.3). On the one hand, green technological innovation has a "prevention effect" on haze pollution, which can reduce haze pollution and improve environmental quality. First, green technology innovation improves production methods, optimizes corporate production structure, and develops cleaner production technologies to solve the problem of haze pollution at the source and reduce the difficulty of back-end governance. Second, green technology innovation improves Energy utilization in the production process to reduce the use of high-polluting energy so as to improve enterprise production 
efficiency and reduce enterprise pollution emissions (Cai and Li, 2018). The above two methods could reduce the main pollutants that form haze from the source emissions, such as $\mathrm{PM}_{2.5}$. Third, through green technological innovation to improve the efficiency of the treatment of pollution that has already occurred, alleviate the degree of haze pollution and achieve the goal of treating haze pollution.

On the other hand, technological innovation may also hinder the treatment of haze pollution to a certain extent. Research by Sun et al. (2012) found that technological progress has increased haze pollution since the 1990s. Li and Zhou (2006) believed that the phenomenon was caused by the "rebound effect" of energy caused by technological progress, that is, on the basis of constant energy prices, green technological innovation has reduced energy consumption per unit of output. However, it will stimulate enterprises to increase the use of energy, resulting in an increase in the final consumption of energy, leading to an increase in pollutant emissions and aggravating haze pollution. Based on the above discussion, it can be seen that the impact of green technological innovation on haze pollution has two sides, and its final impact depends on the combined effect of the "prevention effect" and the "rebound effect".

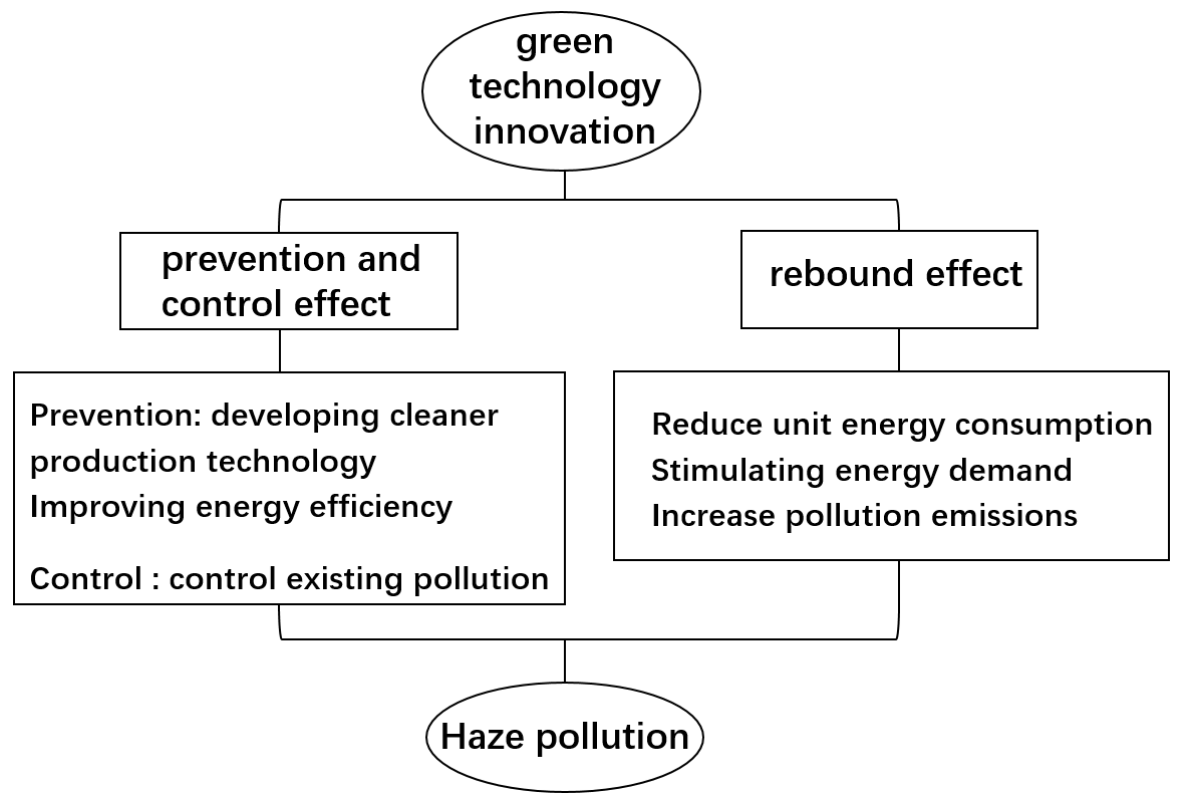

Fig.3 The double impact of green technology innovation on haze pollution

\section{Research model design}

Based on the above theories, a spatial panel model is constructed to empirically estimate the impact of green technology innovation on haze pollution. It is noteworthy that haze pollution is expected to spatially correlate across regions due to atmospheric circulation, industrial transfer and inter-regional traffic flow. Thus, we should consider the spatial characteristics of haze pollution. The results of Xiao et al. (2019) show that there is an 
apparent spatial correlation of green innovation among provinces in China. Moran's I index is used to test whether haze pollution has spatial correlation, and its calculation formula is as follows.

$$
I=\frac{n \sum_{i=1}^{n} \sum_{j=1}^{n} w_{i j}\left(x_{i}-\bar{x}\right)\left(x_{j}-\bar{x}\right)}{\sum_{i=1}^{n} \sum_{j=1}^{n} w_{i j} \sum_{j=1}^{n}\left(x_{i}-\bar{x}\right)^{2}}
$$

Where $n$ is the 30 provinces in mainland China except Tibet. $w_{i j}$ is the spatial weight matrix. $\mathrm{x}$ and $\bar{x}$ are $\mathrm{PM}_{2.5}$ concentrations and their mean values for each province, respectively.

\section{Construction of spatial weight matrix}

In this paper, three spatial weight matrices are structured to measure the spatial correlation of haze pollution (Getis, 2009). Geographic distance weight matrix considers the geographic distance between provinces, which is the reciprocal square of the distance between the geographical centers of provinces $i$ and $j$ (Zhang et al., 2020):

$$
W_{1}=w_{i j}=\left\{\begin{array}{cc}
1 / d_{i j}^{2} \quad i \neq j \\
0 \quad i=j
\end{array}\right.
$$

Where $d_{i j}$ is the distance between the geographic centers of provinces $i$ and $j$.

Economic weight matrix considers the differences in economic development levels between provinces (Du et al., 2018). The more similar the level of economic development is, the greater the spatial weight coefficient is. The formula is as follows:

$$
W_{2}=w_{i j}=\frac{1}{\left|Y_{i}-Y_{j}\right|}
$$

Where $Y$ represents the economic development level of each province, and it is usually expressed by GDP per capita.

Nested weight matrix of geographical and economic distance considers the radiation effect of geographic distance and economic factors. The formula is as follows:

$$
W_{3}=\varphi W_{1}+(1-\varphi) W_{2}
$$

Where $\varphi$ represents the proportion of the geographic distance weight matrix, between $0-1$. In order to simplify the analysis, in this paper, the value of $\varphi$ is 0.5 .

\section{Basic model setting}

In order to better empirically test the impact of green technology innovation on haze emission reduction, on the basis of the above theoretical model, the following basic panel 
model is constructed in this paper:

$$
\begin{aligned}
\ln P M_{i t}= & \gamma_{0}+\gamma_{1} \ln G P_{i t}+\gamma_{2} \ln P D_{i t}+\gamma_{3} \ln A F C_{i t}+\gamma_{4} \ln I S_{i t}+\gamma_{5} \ln E C_{i t} \\
& +\gamma_{6} \ln F D I_{i t}+\varepsilon_{i t}
\end{aligned}
$$

In the above equation, $\ln P M_{\mathrm{i}, \mathrm{t}}$ is the explained variable, indicating the natural logarithm of haze pollution for province $i$ in year $t$, which is measured by $\mathrm{PM}_{2.5}$ concentration in this paper. GP is the core explanatory variable, indicating the degree of green technology innovation, which is measured by the number of green patent applications. The remaining five variables are control variables, respectively: PD is the population density of each province (Liu et al., 2017). AFC represents the air circulation coefficient, which measures the degree of atmospheric circulation between regions. IS represents the industrial structure advanced index, reflecting the level of industrial structure advanced in each province. EC represents energy consumption structure, that is, the proportion of coal consumption in total energy consumption. FDI refers to the proportion of actual use of foreign direct investment in local GDP, which measures the level of regional openness. $\gamma_{0}$ represents the constant term and $\gamma_{1}$ to $\gamma_{6}$ respectively represent the regression coefficient of each variable. $\varepsilon$ represents the random disturbance term. The purpose of this paper is to empirically test green technological innovation, that is, whether the core explanatory variable GP can inhibit haze pollution $\left(\mathrm{PM}_{2.5}\right)$.

\section{Construction of spatial econometric model}

Spatial lag model (SLM), spatial error model (SEM) and spatial Durbin model (SDM) are commonly used spatial econometric models of panel data. They respectively focus on measuring the spatial effects caused by the spatial correlation of the explained variables, error terms and explanatory variables. Their basic forms are as follows (Elhorst, 2014):

( i ) Spatial lag model (SLM)

$$
y=\rho W y+\alpha \tau_{N}+X \beta+\varepsilon
$$

(ii ) Spatial error model (SEM)

$$
y=\alpha \tau_{N}+X \beta+u
$$

The generating process of the disturbance term $\mathrm{u}$ is as follows:

$$
u=\delta W u+\varepsilon
$$

(iii ) Spatial Durbin model (SDM)

$$
y=\rho W y+\alpha \tau_{N}+X \beta+W X \theta+\varepsilon
$$

In above equations, $\mathrm{y}$ is the $\mathrm{N} \times 1$ dimensional vector composed of the explanatory variables. $\mathrm{W}$ is the spatial weight matrix, and $\mathrm{Wy}$ is the endogenous interaction effect 
between dependent variables. $\mathrm{X}$ is the independent variable, which is an $\mathrm{N} \times \mathrm{K}$ dimensional vector. $\mathrm{WX}$ is the exogenous interaction effect between independent variables. $\rho$ is the spatial autoregressive coefficient, represents the degree of spatial relevance, which measures the impact Wy on y. $\tau_{N}$ represents the order unit matrix, which is an $\mathrm{N} \times 1$ dimensional vector associated with the constant parameter $\alpha$ to be estimated. $\theta$ and $\beta$ are $K \times 1$ dimensional vectors with fixed parameters to be estimated. $\delta$ is the spatial autocorrelation coefficient, and $\varepsilon$ is the random error term.

\section{Variable description and data source}

290 This paper selects panel data from 30 provinces in mainland China for 2011-2017 to 291 conduct an empirical study (Tibet has not been included in the study due to lack of data).

292 Due to the late start of $\mathrm{PM}_{2.5}$ monitoring in China, the $\mathrm{PM}_{2.5}$ data used in this paper are 293 from the atmospheric composition analysis group of the United States. Green patent 294 authorization data are from China patent database. The industrial structure advanced index is calculated by using the original data of China Statistical Yearbook and referring to the calculation method proposed by Fu (2010). Other data source from the National Bureau of Statistics of China (NBS), the China Statistical Yearbook (2011-2017) and the EPS (Easy Professional Superior) data platform. Table 1 describes these variables. Table 2 presents the corresponding descriptive statistics of variables.

Table 1 Variable description

\begin{tabular}{|c|c|c|}
\hline Variable & Meaning & Unit \\
\hline PM & $\begin{array}{c}\text { the annual average value of } \mathrm{PM}_{2.5} \text { emissions, measuring the } \\
\text { haze pollution degree }\end{array}$ & $\mathrm{ug} / m^{3}$ \\
\hline GP & $\begin{array}{l}\text { Green patent authorizations, measuring the level of green } \\
\text { technology innovation }\end{array}$ & term \\
\hline PD & $\begin{array}{l}\text { population density, expressed by the ratio of the number of } \\
\text { resident population at the end of the year and the land area of } \\
\text { each province }\end{array}$ & person $/ \mathrm{km}^{2}$ \\
\hline AFC & $\begin{array}{l}\text { air flow coefficient, measuring the degree of air flow between } \\
\text { different regions }\end{array}$ & I \\
\hline ISI & $\begin{array}{l}\text { industrial structure advanced index, measuring the advanced } \\
\text { level of the industrial structure }\end{array}$ & / \\
\hline EC & $\begin{array}{l}\text { energy consumption structure, the proportion of coal } \\
\text { consumption in total energy consumption, measuring the impact } \\
\text { of coal use on haze pollution }\end{array}$ & $\%$ \\
\hline FDI & $\begin{array}{l}\text { the actual use of foreign direct investment as a proportion of } \\
\text { local GDP, measuring the region's openness to the outside world. }\end{array}$ & $\%$ \\
\hline
\end{tabular}


Table 2 Descriptive statistics of variables

\begin{tabular}{cccccc}
\hline Variable & Obs & Mean & Std & Max & Min \\
\hline PM & 210 & 40.33 & 15.42 & 82.2 & 10.2 \\
GP & 210 & 2764.01 & 3411.77 & 18693 & 20.0 \\
PD & 210 & 465.38 & 693.20 & 3825.69 & 8.15 \\
AFC & 210 & 7.35 & 0.75 & 8.52 & 4.4 \\
ISI & 210 & 6.62 & 0.30 & 7.61 & 6.1 \\
EC & 210 & 67.52 & 30.13 & 152.93 & 4.91 \\
FDI & 210 & 2.29 & 2.05 & 12.10 & 0.04 \\
\hline
\end{tabular}

\section{Analysis of empirical results}

Based on model (5), combined with the spatial panel data model, the following investigate the impact of green technology innovation on haze pollution.

\section{Spatial correlation test}

Moran's I test is used to check the existence of spatial autocorrelation in $\ln P M$. The Lagrange Multiplier (LM) test (Anselin, 1988) and the robust LM test (Anselin et al., 1996) are used to justify whether we select a spatially lagged term of $\ln P M$ or a spatial error term. Table 3 reports the test results under three weight matrices, i.e., the geographic distance weight matrix $\left(\mathrm{W}_{1}\right)$, the economic weight matrix $\left(\mathrm{W}_{2}\right)$, and the nested weight matrix of geographical and economic distance $\left(\mathrm{W}_{3}\right)$. The test results show that the Moran's I test statistics are significant at the $1 \%$ level of significance, indicating that haze pollution has significant spatial correlation, in relation to geographical space, economic development level and the comprehensive impact of the two. Under $\mathrm{W}_{1}$ and $\mathrm{W}_{3}$, both LM and robust LM tests show that the null hypotheses of no spatially lagged $\ln P M$ and no spatially lagged error term are rejected at the $1 \%$ level of significance. Under $\mathrm{W}_{2}$, the LM test results further show that the null hypothesis of no spatially lagged $\ln P M$ cannot be rejected and no spatially lagged error term must be rejected, justifying that the spatial error model should be selected.

Table 3 Results of spatial correlation test

\begin{tabular}{cccc}
\hline & Distance $\mathrm{W}_{1}$ & Economic $\mathrm{W}_{2}$ & Nested $\mathrm{W}_{3}$ \\
\hline $\begin{array}{c}\text { Moran's I } \\
\text { LM test: no spatial } \\
\text { error }\end{array}$ & $1.4 \mathrm{e}+05^{* * * *}$ & $175.069^{* * *}$ & $478.594^{* * *}$ \\
$\begin{array}{c}\text { Robust LM test: } \\
\text { no spatial error }\end{array}$ & $68.827^{* * *}$ & $16.174 * * *$ & $208.948^{* * *}$ \\
LM test: no spatial & $62.953^{* * *}$ & $16.679 * * *$ & $205.277^{* * *}$ \\
\hline
\end{tabular}




\begin{tabular}{|c|c|c|c|}
\hline lag & & & \\
\hline $\begin{array}{c}\text { Robust LM test: } \\
\text { no spatial lag }\end{array}$ & $4.108 * *$ & 0.517 & $5.580 * *$ \\
\hline
\end{tabular}

\section{Model selection}

324

As in the previous analysis, there are mainly three spatial measurement models: SLM, SEM and SDM. In order to choose a more suitable model, a spatial diagnostic test is required. Table 4 shows the parameter estimation results of SLM, SEM and SDM models based on $\mathrm{W}_{1}, \mathrm{~W}_{2}$ and $\mathrm{W}_{3}$, respectively. Take the matrix $\mathrm{W}_{3}$ as an example. Firstly, the Hausman test is used to determine whether to choose a random effect or a fixed effect. The results show that the SLM model accepts the null hypothesis of random effects, while the SEM model and SDM model significantly reject the null hypothesis of random effects and fixed effects should be selected. Secondly, based on the choice of fixed effects, a joint significance test should also be performed to further determine whether the model should choose individual fixation, time fixation or dual fixation. The null hypothesis of LR test (indboth/time-both) is that individuals/time fixed effects should be selected. The results of LR test show that SEM model should choose individual fixed effect, while SDM model should choose individual and time double fixed effect. Finally, the LR test is again applied to select the better model. The original hypothesis of LR test (ind-both/ time-both) is that individual/time fixed effects should be selected. The results of LR test show that the SEM model should select individual fixed effects, while the SDM model should select individual and time double fixed effects. Finally, use the LR test again to select a better model. The null hypothesis of this test (SDM-SLM / SDM-SEM) is that the SLM/SEM model should be selected. The test results of SDM model vs. SLM model and SDM model vs. SEM model show that the SDM model has significant advantages, so SDM should be selected. And the results of AIC also support this conclusion. Therefore, under the matrix $\mathrm{W}_{3}$, the SDM model is a better model. In the same way, the same test is performed on the spatial measurement model based on the matrix $\mathrm{W}_{1}$ and $\mathrm{W}_{2}$. The results of Hausman test and LR test show that under the matrix $\mathrm{W}_{1}$, the double fixed SDM model has better fitting degree (According to relevant research, from the perspective of experience, a negative Hausman test can be seen as a signal to reject the original hypothesis, so we should prefer to choose fixed effect. (Lian et al., 2014). Under the matrix $\mathrm{W}_{2}$, the dual-fixed SLM model fits better, which is contrary to the conclusion of the LM test above. Moreover, the value of spatial $\rho$ of the SLM model is not significant. It can be concluded that under the matrix $\mathrm{W}_{2}$, the possibility of the spatial correlation of haze pollution is low. Therefore, the subsequent analysis of the SLM model under the matrix $\mathrm{W}_{2}$ will not be done in the following, but the analysis will be focused on the SDM model under the matrix $\mathrm{W}_{1}$ and $\mathrm{W}_{3}$. Based on the above analysis, regression analysis is performed on models with a higher degree of fit under the matrix $W_{1}$ and $W_{3}$ respectively to explore the haze reduction 
effect of green technological innovation.

Table 4 Spatial diagnostic tests

\begin{tabular}{|c|c|c|c|c|c|c|c|c|c|}
\hline & \multicolumn{3}{|c|}{ Distance $\mathrm{W}_{1}$} & \multicolumn{3}{|c|}{ Economic $\mathrm{W}_{2}$} & \multicolumn{3}{|c|}{ Nested $W_{3}$} \\
\hline & SLM & SEM & SDM & SLM & SEM & SDM & SLM & SEM & SDM \\
\hline Hausman & 5.27 & -17.97 & $\begin{array}{c}24.84 \\
* * *\end{array}$ & -1.39 & 6.67 & -13.48 & 0.70 & $\begin{array}{c}56.88^{* *} \\
*\end{array}$ & $15.59^{* * *}$ \\
\hline & re & fe & fe & fe & re & fe & re & fe & fe \\
\hline $\begin{array}{c}\text { LR test } \\
\text { (ind-both) }\end{array}$ & & 10.26 & $\begin{array}{c}37.12^{* *} \\
*\end{array}$ & $\begin{array}{c}62.76^{* *} \\
*\end{array}$ & & $\begin{array}{l}38.08^{* *} \\
*\end{array}$ & & 9.76 & $\begin{array}{l}58.30^{* *} \\
*\end{array}$ \\
\hline $\begin{array}{l}\text { LR test } \\
\text { (time-both) }\end{array}$ & & $\begin{array}{c}608.77 \\
* * *\end{array}$ & $\begin{array}{c}599.33 \\
* * *\end{array}$ & $\begin{array}{c}589.47 \\
* * *\end{array}$ & & $\begin{array}{c}563.89 \\
* * *\end{array}$ & & $\begin{array}{c}597.67 \\
* * *\end{array}$ & $\begin{array}{c}598.70 \\
* * *\end{array}$ \\
\hline $\begin{array}{c}\text { LR test } \\
\text { (SLM-SDM) }\end{array}$ & & & $\begin{array}{c}220.43 \\
* * *\end{array}$ & & & 8.19 & & & $\begin{array}{c}249.17 \\
* * * *\end{array}$ \\
\hline $\begin{array}{c}\text { LR test } \\
\text { (SEM-SDM) }\end{array}$ & & & $\begin{array}{c}39.93 \\
* * *\end{array}$ & & & $\begin{array}{c}235.97 \\
* * * *\end{array}$ & & & $\begin{array}{c}69.91 \\
* * *\end{array}$ \\
\hline$\rho$ & $\begin{array}{c}0.8190 \\
* * *\end{array}$ & & $\underset{* * *}{0.5257}$ & 0.0256 & & 0.0825 & $\begin{array}{c}0.8467 \\
* * *\end{array}$ & & $\begin{array}{c}0.4132 \\
* *\end{array}$ \\
\hline$\delta$ & & $\begin{array}{c}0.8359 \\
* * *\end{array}$ & & & $\underset{\substack{* * \\
* * *}}{0.5845}$ & & & $\begin{array}{c}0.8607 \\
* * *\end{array}$ & $\begin{array}{c}0.8359 \\
* * *\end{array}$ \\
\hline AIC & $\begin{array}{c}- \\
275.85\end{array}$ & $\begin{array}{c}- \\
460.35\end{array}$ & $\begin{array}{c}- \\
488.28\end{array}$ & $\begin{array}{c}- \\
421.77\end{array}$ & $\begin{array}{c}- \\
190.00\end{array}$ & $\begin{array}{c}- \\
417.97\end{array}$ & $\begin{array}{c}- \\
245.77\end{array}$ & $\begin{array}{c}- \\
429.03\end{array}$ & $\begin{array}{c}- \\
486.95\end{array}$ \\
\hline
\end{tabular}

Note: ${ }^{*},{ }^{* * * * *}$ denote statistical significant at $10 \%, 5 \%$ and $1 \%$ confidence levels respectively.

\section{Regression analysis}

362

363

364

365

366

367

\section{Analysis of regression results}

Based on the results of the spatial diagnostic test, the SDM model under the matrix $\mathrm{W}_{1}$ and the matrix $\mathrm{W}_{2}$ has batter fitting degree for sample data. Therefore, the regression results of the SDM model under the matrix $\mathrm{W}_{1}$ and the matrix $\mathrm{W}_{3}$ are listed, and compared with the OLS results. The specific results are shown in Table 5.

Table 5 Model estimation results

\begin{tabular}{cccc}
\hline Variable & OLS & $\begin{array}{c}\text { SDM model based on } \\
\text { distance } \mathrm{W}_{1}\end{array}$ & $\begin{array}{c}\text { SDM model based on } \\
\text { distance } \mathrm{W}_{3}\end{array}$ \\
\hline $\ln \mathrm{GP}$ & 0.0401 & -0.0626 & $-0.1323^{* * *}$ \\
$\ln \mathrm{PD}$ & $0.2373^{* * *}$ & 0.3167 & 0.6443 \\
$\ln \mathrm{AFC}$ & $-1.9802^{* * *}$ & 0.0739 & 0.1603 \\
$\ln \mathrm{SSI}$ & 0.8033 & 0.1949 & -0.5277 \\
$\operatorname{lnEC}$ & $0.1886^{* * *}$ & $0.0881^{*}$ & $0.1484^{* * *}$ \\
\hline
\end{tabular}




\begin{tabular}{|c|c|c|c|}
\hline$\overline{\operatorname{lnFDI}}$ & $-0.0659^{* *}$ & $-0.0266^{*}$ & $-0.0489^{* * *}$ \\
\hline L. $\operatorname{lnPM}$ & & $0.3397^{* * *}$ & $0.3275^{* * * *}$ \\
\hline$\rho$ & & $0.5257^{* * *}$ & $0.4132^{* *}$ \\
\hline WlnGP & & $-0.4436^{* * *}$ & $-1.9346^{* * *}$ \\
\hline WlnPD & & 1.8510 & $6.6474^{*}$ \\
\hline WlnAFC & & $1.0623^{* *}$ & $2.2868^{* *}$ \\
\hline WlnISI & & $-7.3341^{* * *}$ & $-22.9147^{* * * *}$ \\
\hline WlnEC & & $0.2680^{* *}$ & $1.0582^{* * *}$ \\
\hline WlnFDI & & -0.0740 & $-0.4255^{* * *}$ \\
\hline
\end{tabular}

Note: ${ }^{*},{ }^{* * * * *}$ denote statistical significant at $10 \%, 5 \%$ and $1 \%$ confidence levels respectively.

According to the above regression results, it is found that:

First, ignoring the spatially related effects affects the effect of the explanatory variables on the explained variables and the extent of their effect. First of all, on the coefficient signs of the core explanatory variables, the SDM model based on the matrix $\mathrm{W}_{3}$ has consistent and opposite variable coefficient signs to the OLS model, which shows that when considering the spatial effect, the core explanatory variables will have a completely opposite impact on the explained variables by adding the spatial effect, indicating that the variables and sample data in this study have obvious and non-negligible spatial correlation. And then, on the absolute values of the coefficients of the core explanatory variables, the estimates of the SDM model are greater than those of the OLS model, indicating that the simple non-spatial OLS model underestimates the degree of influence of the core explanatory variables on haze pollution because of ignoring the spatial correlation between the variables.

Second, the spatial correlation of China's haze pollution is significant. The spatial $\rho$ is significantly positive, indicating that the haze pollution between regions has significant spatial correlation and strong spillover effects. Geographical distance and the combined factors of geography and economy are both important factors that affect the degree of regional haze pollution: when the two places are geographically close, the exchange of production and other activities between the two places makes them have more similar haze pollution conditions. It is precisely because of the spillover effect of haze pollution that it is impossible for a region to complete haze control work alone, nor can it be deliberately to improve the local atmospheric environment simply by transferring pollution-intensive industries to neighboring regions. Although this method may temporarily improve the local environmental quality, pollution from neighboring areas will inhibit this improvement. Therefore, the management of haze pollution requires the coordinated participation of multiple entities.

Third, GP, EC and FDI are all conducive to haze reduction. The core explanatory variable GP has a significant inhibitory effect on haze pollution. The estimated results of 
the SDM model based on the matrix $\mathrm{W}_{3}$ show that for every $1 \%$ increase in regional green technology innovation, local haze pollution will be reduced by $0.1323 \%$. In addition, EC and FDI also have different effects on haze pollution: the optimization of EC can effectively reduce haze pollution. For every $1 \%$ reduction in the proportion of coal consumption in total energy consumption, haze pollution is reduced by $0.1484 \%$. This is the same as the research conclusion of Shao et al. (2016). And every 1\% increase in FDI will reduce haze pollution by $0.0489 \%$, which is in line with the "pollution halo" hypothesis: FDI can be achieved by introducing environmentally friendly technologies and products improve the environmental quality of a country. In general, the effect of GP on haze pollution is limited. On the one hand, China's GP is still in the development stage, the level still needs to be improved, and the scale still needs to be expanded. On the other hand, the haze pollution control measures need to be optimized. In the treatment of haze pollution, a multi-pronged approach is needed to coordinately optimize the energy consumption structure and increase the positive spillover of foreign capital to achieve significant results.

Fourth, the time lag of the explanatory variables is significantly positive. Considering that the pollutants of air pollution such as haze are often cumulative, there is a certain "time lag" between cause and effect, that is, when the current haze pollution is at a high level, the haze pollution level of next phase may continue to rise, thus showing a "snowball effect" (Shao et al., 2016). Therefore, the time lag term of the explanatory variable haze pollution is added to the SDM model as an explanatory variable. The results show that haze pollution has a significant time lag. At a significance level of $1 \%$, the previous haze pollution significantly affected the current pollution level, which is manifested in that for every $1 \%$ increase in the previous haze pollution, the current haze pollution will increase by $0.3397 \%$ and $0.3275 \%$ respectively.

\section{Analysis of spillover effects}

Since the coefficients of the explanatory variables in the spatial panel data model do not reflect the spatial effects, the spatial spillover effects of each variable on haze pollution are listed below. The results are shown in Table 5 . As we can see:

First, the symbol correspondence of spillover effect of the two models is consistent, which indicates that the spillover effect is relatively stable and the model has good robustness.

Second, GP has obvious negative spillover effect. The direct effect of GP on haze pollution is not significant in matrix $\mathrm{W}_{1}$. But the spillover effect of it is significant in both matrices, indicating that local GP has a significant inhibitory effect on haze pollution in adjacent regions. GP has the positive externalities of knowledge and technology spillover, and the government should guide it with policies and regulations to give full play to its positive externalities. 
Third, PD, AFC, ISI, EC, and FDI have significant spillover effects on haze pollution. Firstly, the accumulation of population often aggravates haze pollution through consumption, travel, production and so on. The regression results show that PD has a significant positive spillover effect on haze pollution under $\mathrm{W}_{3}$, indicating that population has aggravated haze pollution, which is the same as the research conclusion of Shao et al. (2019). Secondly, AFC promotes similar haze pollution in neighboring areas. Thirdly, Changes in industrial structure has obvious spillover effect on haze pollution. When Zhang et al. (2020) studied the spatial impact of industrial structure on haze pollution, they also came to the conclusion that industrial structure has an inhibitory effect on haze pollution, and further divided industrial structure changes into two major categories: rationalization and upgrading. During the sample period, only the rationalization of the industrial structure played a role in reducing haze. In this paper, due to the rationalization of the industrial structure, every $1 \%$ increase in the local ISI will reduce the haze pollution in neighboring areas by $7.3341 \%$, and reduce the haze pollution in neighboring areas with similar economic development levels by $22.9147 \%$, which has a profound impact. We believe that this is due to the differences in the level of economic and technological development between regions, and the transfer of pollution by the industrial echelon will cause transboundary pollution between regions. The development of local green technology innovation has promoted the higher level of local industrial structure, reduced high-polluting industries transferred to neighboring areas, and reduced haze pollution. Fourthly, the spillover effect of EC on haze pollution is significant. The results of SDM model based on $\mathrm{W}_{1}$ and $\mathrm{W}_{3}$ respectively show that a $1 \%$ decrease in the proportion of coal consumption in total energy consumption will reduce the haze pollution in neighboring areas by $0.2680 \%$, and the decline in neighboring areas with similar economic development levels will be even greater. More, $1.0582 \%$. Currently, coal ranks first in China's energy consumption structure. In the long run, changing the energy consumption structure is the key, but it is difficult to change it in the short term. Then increasing the use of high-quality energy, especially the use of high-quality coal, is the main way to reduce haze in the short term (Ma and Zhang, 2014). Finally, FDI also has a negative spillover effect on haze pollution. For every $1 \%$ increase in FDI, haze pollution in neighboring areas with similar economic development levels will be reduced by $0.4255 \%$.

\section{Analysis of mediating effects}

Mediating effect means that the influence relationship between variables ( $\mathrm{X}$ to $\mathrm{Y}$ ) is not a direct causal chain relationship, but is produced through the indirect influence of one or more variables $(\mathrm{M})$. In this case, we call $\mathrm{M}$ as a mediating variable, and through $\mathrm{M}$ the indirect influence $X$ on $Y$ called the mediation effect.

Based on the regression results of the above spatial panel model, the direct impact of GP on haze pollution is not significant or the degree of impact is not obvious, while the 
control variables of ISI, EC and FDI have considerable impact on haze pollution. Can GP influence changes in the ISI, EC, and FDI to promote the development of haze emission reduction? Combining the "prevention and control effect" and "rebound effect" of GP on the impact mechanism of haze pollution -- the "prevention effect" brought by the development of cleaner production technologies, the improvement of energy utilization efficiency and the improvement of pollution control methods can reduce haze pollution. The increase in energy use efficiency leads to a reduction in unit energy consumption and a reduction in costs. On the contrary, it stimulates the "rebound effect" brought about by the increase in energy demand, which will expand haze pollution. The following applies the intermediary effect model, using ISI, EC and FDI as intermediary variables to explore the transmission mechanism between GP and haze pollution, and broaden the ways to prevent haze pollution.

Simulation study have found that "Bootstrap method" has higher statistical power than other methods of intermediary effect test (Song et al., 2012). Therefore, based on this method, this paper uses Stata14 to test the intermediary effect of sample data. The original hypothesis is that there is no mediating effect. The results are shown in Table 6.

Table 6 Results of the mediating effect test

\begin{tabular}{ccc}
\hline Intermediary variable & Direct effect & Indirect effect \\
\hline ISI & $0.0014^{* * *}$ & $-0.0004^{*}$ \\
EC & $0.0014^{* * *}$ & $-0.0002^{* *}$ \\
FDI & $0.0014^{* * *}$ & -0.0002 \\
\hline
\end{tabular}

Note: ${ }^{*},{ }^{* * * *}$ denote statistical significant at $10 \%, 5 \%$ and $1 \%$ confidence levels respectively.

It can be seen from the results that the direct and indirect effects of I and EC on haze pollution are both significant, indicating that ISI and EC play a part of the mediating role in green technological innovation and haze pollution. The indirect effect of FDI on haze pollution is not significant, but the direct effect is significant, indicating that there is no intermediary effect. The proportion of secondary industry in China's industrial structure and the abnormally high proportion of coal in the energy consumption structure are the important reasons for haze pollution. Therefore, promoting the rationalization of industrial structure, reducing the proportion of pollution-intensive enterprises and increasing energy technology innovation, reducing the use of disposable energy such as coal, realizing energy substitution, and adjusting the energy consumption structure are the keys to achieve haze control (Wei et al., 2015).

\section{Robustness test}

Considering the robustness of the model and preventing accidental conclusion, another measurement model, the GMM model, was chosen to re-estimate the model in this paper, 
and the results are shown in Table 7.

Table 7 Estimation results of robustness test

\begin{tabular}{cc}
\hline Variable & GMM model regression and correlation test results \\
\hline $\operatorname{lnGP}$ & $-0.4022^{* * * *}$ \\
$\operatorname{lnPD}$ & $1.4262^{* * *}$ \\
$\ln \mathrm{FFC}$ & $-6.5353^{* * *}$ \\
$\operatorname{lnISI}$ & $-6.2165^{* *}$ \\
$\operatorname{lnEC}$ & $0.3430^{*}$ \\
$\operatorname{lnFDI}$ & $-0.3396^{* * *}$ \\
Over-identification & 0.1461 \\
Hausman Test & $109.25^{* * *}$ \\
DWH test for heteroskedasticity & \\
Durbin & $122.936^{* * *}$ \\
Wu-Hausman & $645.03^{* * *}$ \\
\hline
\end{tabular}

Note: ${ }^{*}{ }^{* *},{ }^{* * *}$ denote statistical significant at $10 \%, 5 \%$ and $1 \%$ confidence levels respectively.

The results show that under the GMM model, the coefficient signs and statistical significance of the core explanatory variables are completely consistent with the SDM model under matrix $\mathrm{W}_{3}$, and the signs of other control variables are basically the same, meanwhile the significant differences are small. The GMM model passes the overrecognition test, indicating that the instrumental variable PD is appropriate. The Hausman test results indicate that the other explanatory variables are all exogenous, and there is no influence of heteroskedasticity. The results have high reliability. Therefore, the results show that the original model has good robustness and the estimation results have high credibility.

\section{Conclusions and policy implications}

Using the panel data of 30 provinces in mainland China in 2011-2017, we apply spatial models to estimate the impact of GP on haze pollution and its transmission mechanism under alternative spatial weight matrices. Results show that China's haze pollution has a significant spatial correlation. Every $1 \%$ increase in local haze pollution increases haze pollution by $0.5257 \%$ in adjacent areas and by $0.4132 \%$ in the geographically close region with similar economic development. In addition, the time lag of haze pollution will lead to "snowball effect", which means the current haze pollution will have an impact on the next phase of haze pollution. GP is an effective means to prevent and control haze pollution. Every $1 \%$ increase in GP can reduce haze pollution by $0.1323 \%$. Its spatial spillover effect is significant. The improvement of local GP has an evident radiation impact on haze pollution in adjacent areas, specifically manifested in a $0.4436 \%$ reduction in haze pollution in geographically adjacent areas and a $1.9346 \%$ reduction in geographically 
adjacent areas with similar economic development. The spillover effects of EC, FDI, and IS on haze pollution are negative and significant, indicating that the optimization of $\mathrm{EC}$, the increase of foreign investment and the rationalization of industrial structure contributed to the reduction of haze pollution. ISI and EC play a partially mediating role in green technological innovation and haze pollution. PD and AFC have significant positive spatial spillover effects on haze pollution.

The policy implications of this paper are to understand the role of haze pollution inhibition factors, and emphasize the importance of the strengthening of haze pollution contributory factors, which means to better play the role of "prevention and control effect" of green technology innovation and to reduce the negative impact of the "rebound effect". In terms of promoting the enhancement of inhibiting factors: first, vigorously promote green technology innovation. Second, encourage the private sector, such as enterprises, to engage in green technology innovation and give full play to the role of environmental policy tools to the externalities of environmental innovation (Liao, 2018), and to reduce barriers to innovation (Gupta and Barua, 2018). Third, increase support for green technology innovation in public institutions, higher education institutions and other departments. Fourth, introduce high-quality foreign investment and appropriately increase the guidance in the use of foreign capital. Fifth, guide foreign investment in favor of environmentally friendly technologies and high value-added products. Finally, give full play to regional synergies, and undertake joint efforts to prevent and control haze pollution, and build a collaborative governance system with the participation of multiple entities (Yin et al., 2020). With local governments in the leading role, cooperation in haze control among regions should be strengthened. At the same time, the power of enterprises should be connected, the common interest network of all subjects established, and knowledge sharing realized (Arfi et al., 2018). In terms of inhibiting the enhancement of pollution contributory factors: efforts should be directed towards reducing the generation of haze pollution in production and promoting the rational upgrading of industrial structure. Rational upgrading does not constitute blind demand for the reduction of secondary industry and the expansion of tertiary industry, but aims to make secondary industry more environmentally friendly and reduce the damage of industrial pollution to the atmospheric environment. By optimizing the energy structure, reducing the consumption of fossil energy, developing clean energy and increasing the promotion and popularization of clean energy and realizing energy substitution earlier. In addition, the aim should be to reduce the generation of haze pollution in daily life: raising public awareness of energy conservation and environmental protection, improve the utilization rate of public transport, and reduce the pollution of the atmosphere caused by automobile exhaust. 
568 Ethics approval and consent to participate (Not applicable)

569 Consent for publication (Not applicable)

Availability of data and materials

571

572

573

574

575

576

577

578

579

580

581

582

583

584

585

586

587

588

589

590

591

592

593

594

595

596

The datasets used and/or analysed during the current study are available from the corresponding author on reasonable request.

\section{Competing interests}

The authors declare that they have no competing interests

\section{Funding}

This research was supported by the Open Funds (Grant No. HBQY2021z06) of Regional Innovation Capabilities Monitoring and Analysis Soft Science Research Base of Hubei Province.

\section{Authors' contributions}

Ming Yi identified the topic and the basic framework of this paper and revised the paper at a later stage; Ying Lu gathered data for the writing, completed the first draft of the entire paper and was responsible for formatting edits; Le Wen made repeated revisions to the empirical part of the paper; Ying Luo proposed revisions to the thesis; Shujing $\mathrm{Xu}$ completed the retouching of the translation of the paper; Tian Zhang proposed revisions to the paper.

\section{Acknowledgements}

Thanks for all authors joint efforts. And it will be supplemented after the funding fund is determined

\section{References}

Anselin L (1988) Spatial Econometrics: Methods and Models. Kluwer Academic Publishers. https://doi. org/10.1007/978-94-015-7799-1.

Anselin L, Bera AK, Florex R, Yoon MJ (1996) Simple diagnostic tests for spatial dependence. Reg Sci Urban Econ 26: 77-104. https://doi.org/10.1016/01660462(95) 02111-6 
Apergis N, Eleftheriou S, Payne JE (2013) The relationship between international financial reporting standards, carbon emissions, and R\&D expenditures: Evidence from European manufacturing firms. Ecol Econ 88(4): 57-66. https://doi.org/10.1016/j. ecolecon.2012.12.024

Arfi WB, Hikkerova L, Sahut JM (2018) External knowledge sources, green innovation and performance. Technol Forecast Soc Change 129. https://doi.org/10.1016/j.techfore. 2017.09.017

Braun E, Wield D (1994) Regulation as a means for the social control of technology. Technol Anal Strateg 6(3): 259-272. https://doi.org/10.1080/09537329408524171

Brunnermeier SB, Cohen MA (2003) Determinants of environmental innovation in US manufacturing industries. J Environ Econ Manag 45(2): 278-293. https://doi.org/10. $\underline{1016 / S 0095-0696(02) 00058-X}$

Cai WG, Li GP (2018) The drivers of eco-innovation and its impact on performance: Evidence from China. J Clean Prod 176. https://doi.org/10.1016/j.jclepro.2017.12.109

Chen HB, Wang XL (1998) Green innovation and its incentive mechanism. Shanghai Manag Sci (06): 10-11

Chen SY, Chen DK (2018) Haze pollution, government governance and high-quality economic development. Econ Res J 53(02): 20-34

Chun-Chung A, Vernon HJ (2006) Are Chinese Cities Too Small? Rev Econ Stud 73(3): 549576. https://doi.org/10.1111/j.1467-937X.2006.00387.x

Du G, Liu SZ, Lei N, Yong H (2018) A test of environmental Kuznets curve for haze pollution in China: Evidence from the penal data of 27 capital cities. J Clean Prod 205: 821-827. https://doi.org/10.1016/j.jclepro.2018.08.330

Du K, Li PZ, Yan ZM (2019) Do green technology innovations contribute to carbon dioxide emission reduction? Empirical evidence from patent data. Technol Forecast Soc Change 146: 297-303. https://doi.org/10.1016/j.techfore.2019.06.010

Elhorst JP (2014) Spatial Econometrics. Springer Berlin Heidelberg. https://doi.org/10. 1007/978-3-642-40340-8.

Fisher-Vanden K, Jefferson GH, Ma JK, Xu JY (2006) Technology development and energy productivity in China. Energy Econ 28(5-6): 690-705. https://doi.org/10.1016/j.eneco. 2006.05.006

Fu LH (2010) Empirical Study on the relationship between the upgrading of industrial structure and economic growth in China. Stat Res 27 (08): 79-81. https://doi.org/10. 19343/ j.cnki.11-1302/c.2010.08.011

Garbaccio RF, Ho MS, Jorgenson DW (1999) Why has the energy-output ratio fallen in China. Energy J 20(3): 63-92. https://doi.org/10.5547/ISSN0195-6574-EJ-Vol20-No3-3 
Getis A (2009) Spatial weights matrices. Geogr Anal 41(4): 404-410. https://doi.org/10. 1111/j. 1538-4632.2009.00768.x

Guan DB, Su X, Zhang Q, Peters G, Liu Z, Lei Y, He K (2014) The socioeconomic drivers of China's primary $\mathrm{PM}_{2.5}$ emissions. Environ Res Lett 9(2): 24010.https://doi.org/10. 1088/1748-9326/9/2/024010

Gupta H, Barua MK (2018) A framework to overcome barriers to green innovation in SMEs using BWM and Fuzzy TOPSIS. Sci Total Environ 633. https://doi.org/10.1016/j. scitotenv.2018.03.173

Honjo K (1996) R\&D for technology to solve global warming. J Mater Process Technol 59(3): 218-220. https://doi.org/10.1016/0924-0136(95)02134-5

Leeuwen G, Mohen P (2013) Revisiting the Porter Hypothesis: An empirical analysis of green innovation for the Netherlands. Econ Innov New Technol 67(2): 295-319. https://doi.org/10.1080/10438599.2016.1202521

Lian YJ, Wang WD, Ye RC (2014) Monte Carlo simulation analysis of Hausman test statistic validity. J Appl Stat Manag 33(05): 830-841. https://doi.org/10.13860/j.cnki.sltj20140922-024

Liao ZJ (2018) Content analysis of China's environmental policy instruments on promoting firms' environmental innovation. Environ Sci Policy 88(SI): 46-51. https://doi.org/10. 1016/j.envsci.2018.06.013

Li LS, Zhou Y (2006) Can technological progress improve energy efficiency? --An empirical test based on China's industrial sector. Manag World (10): 82-89. https://doi.org/10. 19744/j. cnki.11-1235/f.2006.10.010

Li MC, Mao CM (2020) Spatial effect of industrial energy consumption structure and transportation on haze pollution in Beijing-Tianjin-Hebei region. Int J Environ Res Public Health 17 (15). https://doi.org/10.3390/ijerph17155610

Liu HM, Fang CL, Zhang XL, Wang ZY, Bao C, Li FZ (2017) The effect of natural and anthropogenic factors on haze pollution in Chinese cities: A spatial econometrics approach. J Cleaner Prod 165: 323-333. https://doi.org/10.1016/j.jclepro.2017.07.127

Liu XH (2018a) Dynamic evolution, spatial spillover effect of technological innovation and haze pollution in China. Energy Environ 29(6): 968-988. https://doi.org/10.1177/ 0958305X18765249

Liu XH (2018b) Effect of energy development and technological innovation on $\mathrm{PM}_{2.5}$ in China: A spatial durbin econometric analysis. Discrete Dyn Nat Soc. https://doi.org/10. $1155 / 2018 / 2148318$

Luo LW, Liang SR (2016) Study on the efficiency and regional disparity of green technology innovation in China's industrial companies. Chine J Popul Res Environ 14(4): 262-270. 
Ma LM, Liu SL, Zhang X (2016) Energy structure, traffic patterns and haze pollution--a study based on spatial econometric model. Financ Trade Econ 37(01): 147-160. https:// doi.org/10.19795/j.cnki.cn11-1166/f.2016.01.012

Ma LM, Zhang X (2014) Spatial effects, economic and energy structure impacts of haze pollution in China. Chin Ind Econ (04): 19-31. https://doi.org/10.19581/j.cnki.ciejournal. 2014.04.002

Ramanathan V, Crutzen PJ, Lelieveld J, et al (2001) Indian Ocean Experiment: An integrated analysis of the climate forcing and effects of the great Indo-Asian haze[J]. J Geophys Res-Atmos 106(D22): 28371-28398. https://doi.org /10.1029/2001JD900133

Shao S, Li X, Cao JH, Yang LL (2016) Economic policy options for haze pollution control in China -- A perspective based on spatial spillover effects. Econ Res 51(09): 73-88.

Shi Q, Lai XD (2013) Identifying the underpin of green and low carbon technology innovation research: A literature review from 1994 to 2010. Technol Forecast Soc Change 80(5): 839-864. https://doi.org/10.1016/j.techfore.2012.09.002

Song M, Fisher R, Kwoh Y (2019) Technological challenges of green innovation and sustainable resource management with large scale data. Technol Forecast Soc Change 144. https://doi.org/10.1016/j.techfore.2018.07.055

Song S, Ritov Y, Haerdle WK (2012) Bootstrap confidence bands and partial linear quantile regression. Journal of Multivariate Anal 107: 244-262. https://doi.org/10.1016/j.jmva. 2012.01.020

Sun GS, Huang Y, Tian HF, Wang FP (2012) Total factor productivity, input substitution and inter regional energy efficiency. Econ Res 47 (09): 99-112.

Wang QH, Qu JS, Wang B, Wang PL (2019) Green technology innovation development in China in 1990-2015. Sci Total Environ 696: 134008. https://doi.org/10.1016/j.scitotenv. 2019.134008

Wei WX, Ma XL (2015) Optimal policy choice for energy structure adjustment and haze control. Chin popul res environ 25(07): 6-14. https://doi.org/10.3969/j.issn.1002-2104. 2015.07.002

Wurlod JD, Noailly J (2018) The impact of green innovation on energy intensity: An empirical analysis for 14 industrial sectors in OECD countries. Energy Econ 71: 47-61. https://doi.org/10.1016/j.eneco.2017.12.012

Xiao LM, Li HX, Xiao QL, Zhang RJ (2019) Synergy and interaction between regional green innovation and green development in China: Based on the test of coupling coordination and pvar model. Sci Technol Manag Res 39 (20): 9-20.

Xie RH, Yuan YJ, Huang JJ (2017) Different types of environmental regulations and heterogeneous influence on "green" productivity: Evidence from China. Ecol Econ 132: 104-112. https://doi.org/ 10.1016/j.ecolecon.2016.10.019 
Xu HL, Deng YP (2014) An Empirical Study of Foreign Direct Investment and Resource and Environmental Performance. J Quant Tech Econ 31 (01): 3-21+41. https://doi.org/ 10.13653/j.cnki.jqte.2014.01.001

Yi M, Wang YQ, Sheng MY, Sharp B, Zhang Y (2020) Effects of heterogeneous technological progress on haze pollution: Evidence from China. Ecol Econ 169. https://doi.org/10. 1016/j.ecolecon.2019.106533

Yin S, Zhang N, Li BZ (2020) Improving the effectiveness of multi-agent Cooperation for green manufacturing in China: A theoretical framework to measure the performance of green technology innovation. Int J Environ Res Public Health 17(9). https://doi.org/ 10. 3390/ijerph17093211

Zhang M, Sun X, Wang W (2020) Study on the effect of environmental regulations and industrial structure on haze pollution in China from the dual perspective of independence and linkage. J Cleaner Prod 256. https://doi.org/10.1016/j.jclepro.2020. 120748

Zhang XD, Chen LL, Yuan RS (2020) Effect of natural and anthropic factors on the spatiotemporal pattern of haze pollution control of China. J Cleaner Prod 251. https:// doi.org/ 10.1016/j.jclepro.2019.119531

Appendix

Raw Data:

\begin{tabular}{|c|c|c|c|c|c|c|c|c|c|}
\hline & $\begin{array}{l}\text { Prov } \\
\text { ince }\end{array}$ & Year & $\begin{array}{l}\mathrm{PM}_{2.5} \\
\text { (ug } \\
/ \mathrm{m}^{3} \text { ) }\end{array}$ & $\begin{array}{c}\text { GP } \\
\text { (term) }\end{array}$ & $\begin{array}{c}\mathrm{PD} \\
\text { (person/ } \\
\mathrm{km}^{2} \text { ) }\end{array}$ & $\mathrm{AFC}$ & ISI & $\begin{array}{l}\text { EC } \\
(\%)\end{array}$ & $\begin{array}{l}\text { FDI } \\
(\%)\end{array}$ \\
\hline 1 & \multirow{7}{*}{$\begin{array}{c}\text { Beiji } \\
\text { ng }\end{array}$} & 2011 & 52.1 & 3919 & 1230.06 & 8.11 & 7.5293 & 24.15 & 2.65 \\
\hline 1 & & 2012 & 45.2 & 5088 & 1260.96 & 7.67 & 7.5339 & 22.59 & 2.67 \\
\hline 1 & & 2013 & 55.2 & 7588 & 1288.68 & 7.27 & 7.5420 & 21.45 & 2.50 \\
\hline 1 & & 2014 & 52.4 & 9341 & 1311.11 & 7.69 & 7.5612 & 18.16 & 2.42 \\
\hline 1 & & 2015 & 51.1 & 11143 & 1322.68 & 7.67 & 7.5899 & 12.14 & 3.27 \\
\hline 1 & & 2016 & 47.4 & 12094 & 1323.90 & 7.89 & 7.5997 & 8.70 & 3.20 \\
\hline 1 & & 2017 & 48.8 & 11769 & 1322.68 & 7.67 & 7.6096 & 4.91 & 5.50 \\
\hline 2 & & 2011 & 71.1 & 991 & 1138.66 & 8.21 & 6.9463 & 49.47 & 10.39 \\
\hline
\end{tabular}




\begin{tabular}{|c|c|c|c|c|c|c|c|c|c|}
\hline 2 & \multirow{6}{*}{$\begin{array}{c}\text { Tianj } \\
\text { in }\end{array}$} & 2012 & 60.3 & 1477 & 1187.52 & 7.70 & 6.9644 & 46.11 & 10.48 \\
\hline 2 & & 2013 & 82.2 & 2026 & 1237.15 & 7.21 & 6.9879 & 47.84 & 10.48 \\
\hline 2 & & 2014 & 76.9 & 2259 & 1274.79 & 7.56 & 7.0173 & 44.09 & 10.89 \\
\hline 2 & & 2015 & 69.8 & 3062 & 1300.00 & 7.65 & 7.0700 & 39.25 & 12.10 \\
\hline 2 & & 2016 & 67.3 & 3960 & 1312.61 & 7.87 & 7.1598 & 36.65 & 5.85 \\
\hline 2 & & 2017 & 68.4 & 4120 & 1308.40 & 7.62 & 7.1601 & 34.56 & 5.75 \\
\hline 3 & \multirow{7}{*}{$\begin{array}{c}\text { Hebe } \\
\text { i }\end{array}$} & 2011 & 51.0 & 739 & 400.03 & 7.65 & 6.3658 & 74.56 & 1.41 \\
\hline 3 & & 2012 & 47.9 & 1192 & 402.62 & 7.51 & 6.3757 & 74.05 & 1.59 \\
\hline 3 & & 2013 & 58.6 & 1581 & 405.12 & 7.14 & 6.3653 & 76.24 & 1.65 \\
\hline 3 & & 2014 & 54.4 & 1657 & 407.94 & 7.34 & 6.4226 & 72.20 & 1.55 \\
\hline 3 & & 2015 & 52.2 & 2298 & 410.21 & 7.33 & 6.4866 & 70.33 & 1.46 \\
\hline 3 & & 2016 & 49.7 & 2818 & 412.69 & 7.64 & 6.5332 & 67.38 & 1.72 \\
\hline 3 & & 2017 & 51.5 & 3260 & 415.46 & 7.23 & 6.5148 & 64.45 & 1.87 \\
\hline 4 & \multirow{7}{*}{$\begin{array}{c}\text { Shan } \\
\text { xi }\end{array}$} & 2011 & 40.0 & 421 & 230.32 & 7.02 & 6.5862 & 130.57 & 1.23 \\
\hline 4 & & 2012 & 37.5 & 531 & 231.46 & 7.38 & 6.6490 & 127.64 & 1.35 \\
\hline 4 & & 2013 & 43.7 & 742 & 232.69 & 7.24 & 6.6638 & 132.43 & 1.45 \\
\hline 4 & & 2014 & 37.6 & 828 & 233.85 & 7.48 & 6.7517 & 135.17 & 1.50 \\
\hline 4 & & 2015 & 36.5 & 864 & 234.87 & 7.42 & 6.9401 & 136.77 & 1.51 \\
\hline 4 & & 2016 & 33.8 & 1004 & 236.03 & 7.46 & 6.9928 & 131.15 & 1.30 \\
\hline 4 & & 2017 & 36.7 & 1142 & 237.31 & 7.41 & 6.9490 & 152.93 & 0.79 \\
\hline 5 & \multirow{7}{*}{$\begin{array}{l}\text { Nei } \\
\text { men } \\
\text { ggu }\end{array}$} & 2011 & 20.6 & 154 & 20.98 & 7.08 & 6.4649 & 132.22 & 2.62 \\
\hline 5 & & 2012 & 20.0 & 194 & 21.05 & 7.40 & 6.4743 & 132.20 & 2.38 \\
\hline 5 & & 2013 & 23.4 & 270 & 21.12 & 6.63 & 6.4810 & 141.06 & 2.52 \\
\hline 5 & & 2014 & 23.2 & 347 & 21.17 & 7.35 & 6.5492 & 142.27 & 2.01 \\
\hline 5 & & 2015 & 24.9 & 499 & 21.22 & 7.37 & 6.5720 & 137.75 & 1.62 \\
\hline 5 & & 2016 & 21.2 & 559 & 21.30 & 7.55 & 6.6442 & 134.64 & 1.91 \\
\hline 5 & & 2017 & 27.1 & 649 & 21.38 & 7.54 & 6.6296 & 138.43 & 1.43 \\
\hline 6 & & 2011 & 32.8 & 1294 & 296.15 & 7.80 & 6.5152 & 56.78 & 9.58 \\
\hline
\end{tabular}




\begin{tabular}{|c|c|c|c|c|c|c|c|c|c|}
\hline 6 & \multirow{6}{*}{$\begin{array}{l}\text { Liao } \\
\text { ning }\end{array}$} & 2012 & 27.8 & 1707 & 296.55 & 7.65 & 6.5388 & 55.32 & 9.48 \\
\hline 6 & & 2013 & 36.1 & 1910 & 296.62 & 7.36 & 6.5536 & 59.63 & 9.36 \\
\hline 6 & & 2014 & 40.9 & 1714 & 296.72 & 8.14 & 6.6358 & 58.98 & 8.41 \\
\hline 6 & & 2015 & 43.4 & 2086 & 296.11 & 7.94 & 6.7184 & 57.15 & 1.60 \\
\hline 6 & & 2016 & 33.5 & 2292 & 295.84 & 8.06 & 6.7887 & 57.55 & 0.98 \\
\hline 6 & & 2017 & 36.8 & 2487 & 295.23 & 8.04 & 6.7689 & 58.28 & 1.66 \\
\hline 7 & \multirow{7}{*}{ Jilin } & 2011 & 24.4 & 374 & 147.03 & 6.91 & 6.3628 & 86.59 & 1.24 \\
\hline 7 & & 2012 & 21.6 & 425 & 147.08 & 7.23 & 6.3711 & 83.84 & 1.20 \\
\hline 7 & & 2013 & 29.3 & 499 & 147.13 & 7.06 & 6.3924 & 86.04 & 1.20 \\
\hline 7 & & 2014 & 35.4 & 493 & 147.17 & 7.64 & 6.4251 & 86.61 & 1.21 \\
\hline 7 & & 2015 & 38.2 & 705 & 147.22 & 7.42 & 6.4618 & 86.02 & 1.32 \\
\hline 7 & & 2016 & 28.6 & 781 & 146.15 & 7.54 & 6.5805 & 83.93 & 1.45 \\
\hline 7 & & 2017 & 34.8 & 873 & 145.29 & 7.62 & 6.5192 & 83.37 & 1.38 \\
\hline 8 & \multirow{7}{*}{$\begin{array}{l}\text { Heil } \\
\text { ongji } \\
\text { ang }\end{array}$} & 2011 & 14.7 & 715 & 84.45 & 6.99 & 6.3423 & 77.80 & 2.11 \\
\hline 8 & & 2012 & 14.2 & 916 & 84.45 & 7.28 & 6.3649 & 78.19 & 2.23 \\
\hline 8 & & 2013 & 18.9 & 1183 & 84.47 & 7.06 & 6.3216 & 79.95 & 2.41 \\
\hline 8 & & 2014 & 26.5 & 1100 & 84.43 & 7.58 & 6.4277 & 81.23 & 2.57 \\
\hline 8 & & 2015 & 25.0 & 1387 & 83.96 & 7.23 & 6.5515 & 79.13 & 2.90 \\
\hline 8 & & 2016 & 20.2 & 1533 & 83.68 & 7.72 & 6.6429 & 81.63 & 3.25 \\
\hline 8 & & 2017 & 28.1 & 1568 & 83.46 & 7.59 & 6.5665 & 82.44 & 3.21 \\
\hline 9 & \multirow{7}{*}{$\begin{array}{l}\text { Shan } \\
\text { ghai }\end{array}$} & 2011 & 47.4 & 2841 & 3702.33 & 8.49 & 7.2058 & 38.93 & 4.07 \\
\hline 9 & & 2012 & 41.3 & 3455 & 3754.33 & 8.40 & 7.2556 & 35.85 & 4.50 \\
\hline 9 & & 2013 & 52.1 & 3891 & 3809.08 & 7.99 & 7.2902 & 35.77 & 4.48 \\
\hline 9 & & 2014 & 51.3 & 3732 & 3825.69 & 8.24 & 7.3420 & 31.55 & 4.42 \\
\hline 9 & & 2015 & 53.7 & 4632 & 3808.35 & 8.22 & 7.3994 & 29.66 & 4.28 \\
\hline 9 & & 2016 & 44.8 & 5537 & 3816.23 & 8.27 & 7.4347 & 28.21 & 4.11 \\
\hline 9 & & 2017 & 57.6 & 6039 & 3813.08 & 8.14 & 7.4545 & 27.57 & 3.49 \\
\hline 10 & & 2011 & 58.7 & 5175 & 766.87 & 8.14 & 6.7092 & 70.85 & 4.25 \\
\hline
\end{tabular}




\begin{tabular}{|c|c|c|c|c|c|c|c|c|c|}
\hline 10 & \multirow{6}{*}{$\begin{array}{c}\text { Jiang } \\
\mathrm{su}\end{array}$} & 2012 & 49.6 & 7447 & 768.93 & 8.16 & 6.7270 & 68.74 & 4.20 \\
\hline 10 & & 2013 & 61.3 & 10641 & 770.82 & 7.56 & 6.7551 & 68.35 & 3.47 \\
\hline 10 & & 2014 & 63.5 & 10132 & 772.82 & 7.81 & 6.8238 & 64.37 & 2.67 \\
\hline 10 & & 2015 & 61.8 & 13554 & 774.37 & 7.76 & 6.8543 & 64.28 & 2.12 \\
\hline 10 & & 2016 & 54.7 & 15575 & 776.61 & 8.10 & 6.8969 & 64.52 & 2.11 \\
\hline 10 & & 2017 & 63.5 & 16615 & 779.52 & 7.83 & 6.9229 & 60.50 & 1.98 \\
\hline 11 & \multirow{7}{*}{$\begin{array}{c}\text { Zheji } \\
\text { ang }\end{array}$} & 2011 & 34.2 & 4150 & 535.59 & 7.83 & 6.7828 & 59.20 & 2.37 \\
\hline 11 & & 2012 & 34.2 & 6024 & 536.96 & 7.73 & 6.8131 & 56.80 & 2.40 \\
\hline 11 & & 2013 & 37.2 & 8165 & 539.02 & 7.22 & 6.8314 & 54.27 & 2.35 \\
\hline 11 & & 2014 & 38.5 & 7546 & 540.00 & 7.52 & 6.8808 & 52.45 & 2.42 \\
\hline 11 & & 2015 & 34.1 & 10566 & 543.04 & 7.42 & 6.9241 & 50.36 & 2.43 \\
\hline 11 & & 2016 & 28.0 & 12103 & 548.04 & 7.59 & 6.9524 & 49.14 & 2.47 \\
\hline 11 & & 2017 & 36.2 & 11933 & 554.61 & 7.35 & 6.9674 & 48.44 & 2.31 \\
\hline 12 & \multirow{7}{*}{$\begin{array}{c}\text { Anh } \\
\text { ui }\end{array}$} & 2011 & 52.5 & 1137 & 429.35 & 8.07 & 6.2866 & 95.44 & 2.63 \\
\hline 12 & & 2012 & 47.7 & 1814 & 430.79 & 8.02 & 6.3078 & 92.47 & 2.97 \\
\hline 12 & & 2013 & 55.5 & 2537 & 433.80 & 7.44 & 6.3248 & 95.67 & 3.22 \\
\hline 12 & & 2014 & 60.9 & 2762 & 437.63 & 7.69 & 6.3936 & 93.89 & 3.37 \\
\hline 12 & & 2015 & 53.7 & 3657 & 442.01 & 7.65 & 6.4744 & 90.77 & 3.56 \\
\hline 12 & & 2016 & 48.1 & 4408 & 445.76 & 7.96 & 6.5366 & 88.50 & 3.73 \\
\hline 12 & & 2017 & 59.6 & 4356 & 450.00 & 7.75 & 6.5037 & 88.03 & 3.62 \\
\hline 13 & \multirow{7}{*}{$\begin{array}{c}\text { Fujia } \\
\text { n }\end{array}$} & 2011 & 20.4 & 1171 & 306.43 & 7.12 & 6.5432 & 58.43 & 2.24 \\
\hline 13 & & 2012 & 20.3 & 1567 & 308.73 & 6.83 & 6.5507 & 54.19 & 1.98 \\
\hline 13 & & 2013 & 20.5 & 1991 & 310.87 & 7.05 & 6.5513 & 51.57 & 1.84 \\
\hline 13 & & 2014 & 22.3 & 1890 & 313.51 & 7.39 & 6.5781 & 48.36 & 1.75 \\
\hline 13 & & 2015 & 20.0 & 3141 & 316.23 & 7.19 & 6.6245 & 44.92 & 1.78 \\
\hline 13 & & 2016 & 18.3 & 4671 & 319.11 & 7.06 & 6.6518 & 39.46 & 1.84 \\
\hline 13 & & 2017 & 22.9 & 4298 & 322.16 & 7.11 & 6.6398 & 41.80 & 1.71 \\
\hline 14 & & 2011 & 35.2 & 351 & 268.77 & 7.99 & 6.3464 & 72.05 & 3.38 \\
\hline
\end{tabular}




\begin{tabular}{|c|c|c|c|c|c|c|c|c|c|}
\hline 14 & \multirow{6}{*}{$\begin{array}{c}\text { Jiang } \\
\text { xi }\end{array}$} & 2012 & 35.9 & 487 & 269.70 & 7.76 & 6.3719 & 67.17 & 3.36 \\
\hline 14 & & 2013 & 36.2 & 655 & 270.79 & 7.28 & 6.3915 & 68.34 & 3.27 \\
\hline 14 & & 2014 & 40.2 & 693 & 271.99 & 7.48 & 6.4464 & 66.31 & 3.31 \\
\hline 14 & & 2015 & 33.9 & 1173 & 273.43 & 7.45 & 6.4943 & 65.15 & 3.52 \\
\hline 14 & & 2016 & 32.5 & 1665 & 274.98 & 7.53 & 6.5634 & 62.21 & 3.77 \\
\hline 14 & & 2017 & 40.0 & 1771 & 276.78 & 7.41 & 6.5888 & 61.63 & 3.83 \\
\hline 15 & \multirow{7}{*}{$\begin{array}{l}\text { Shan } \\
\text { dong }\end{array}$} & 2011 & 64.7 & 3028 & 613.82 & 8.04 & 6.5390 & 74.87 & 1.85 \\
\hline 15 & & 2012 & 62.3 & 4009 & 616.88 & 7.88 & 6.5802 & 73.88 & 1.82 \\
\hline 15 & & 2013 & 72.4 & 5042 & 619.96 & 7.24 & 6.6001 & 76.13 & 1.84 \\
\hline 15 & & 2014 & 70.3 & 4991 & 623.53 & 7.93 & 6.6676 & 77.40 & 1.84 \\
\hline 15 & & 2015 & 69.2 & 7022 & 627.23 & 7.90 & 6.7122 & 77.04 & 1.84 \\
\hline 15 & & 2016 & 62.9 & 8774 & 633.59 & 7.90 & 6.7650 & 75.52 & 1.90 \\
\hline 15 & & 2017 & 62.8 & 8791 & 637.35 & 7.84 & 6.7963 & 70.47 & 1.91 \\
\hline 16 & \multirow{7}{*}{$\begin{array}{c}\text { Hena } \\
\mathrm{n}\end{array}$} & 2011 & 66.6 & 1376 & 562.16 & 7.68 & 6.2487 & 87.88 & 2.47 \\
\hline 16 & & 2012 & 61.9 & 1727 & 563.23 & 7.50 & 6.2764 & 76.24 & 2.64 \\
\hline 16 & & 2013 & 74.7 & 2197 & 563.65 & 7.05 & 6.2980 & 81.70 & 2.63 \\
\hline 16 & & 2014 & 66.7 & 2250 & 565.03 & 7.46 & 6.4121 & 75.67 & 2.65 \\
\hline 16 & & 2015 & 66.0 & 3061 & 567.66 & 7.57 & 6.4899 & 73.15 & 2.70 \\
\hline 16 & & 2016 & 58.5 & 3498 & 570.78 & 7.80 & 6.5494 & 71.77 & 2.80 \\
\hline 16 & & 2017 & 63.3 & 3917 & 572.40 & 7.44 & 6.5500 & 70.58 & 2.59 \\
\hline 17 & \multirow{7}{*}{$\begin{array}{c}\text { Hub } \\
\text { ei }\end{array}$} & 2011 & 53.0 & 1262 & 309.54 & 8.07 & 6.3686 & 68.10 & 1.51 \\
\hline 17 & & 2012 & 47.2 & 1557 & 310.70 & 7.88 & 6.3782 & 63.85 & 1.58 \\
\hline 17 & & 2013 & 52.7 & 2196 & 311.77 & 7.37 & 6.4083 & 55.34 & 1.68 \\
\hline 17 & & 2014 & 54.6 & 2261 & 312.69 & 7.68 & 6.5102 & 52.03 & 1.72 \\
\hline 17 & & 2015 & 50.7 & 2917 & 314.62 & 7.57 & 6.5572 & 51.23 & 1.84 \\
\hline 17 & & 2016 & 42.9 & 3524 & 316.40 & 7.76 & 6.5744 & 49.54 & 2.02 \\
\hline 17 & & 2017 & 46.8 & 3945 & 317.31 & 7.57 & 6.5745 & 49.05 & 1.99 \\
\hline 18 & & 2011 & 46.0 & 1181 & 311.41 & 8.10 & 6.3632 & 57.48 & 2.10 \\
\hline
\end{tabular}




\begin{tabular}{|c|c|c|c|c|c|c|c|c|c|}
\hline 18 & \multirow{6}{*}{$\begin{array}{l}\text { Hun } \\
\text { an }\end{array}$} & 2012 & 47.5 & 1531 & 313.45 & 7.90 & 6.3951 & 51.55 & 2.18 \\
\hline 18 & & 2013 & 45.3 & 2024 & 315.89 & 7.30 & 6.4530 & 53.74 & 2.29 \\
\hline 18 & & 2014 & 49.9 & 1984 & 318.09 & 7.68 & 6.5250 & 50.83 & 2.44 \\
\hline 18 & & 2015 & 42.1 & 2666 & 320.26 & 7.57 & 6.5697 & 51.45 & 2.52 \\
\hline 18 & & 2016 & 37.5 & 2834 & 322.11 & 7.75 & 6.6264 & 51.72 & 2.77 \\
\hline 18 & & 2017 & 41.4 & 3247 & 323.90 & 7.59 & 6.6450 & 54.79 & 2.89 \\
\hline 19 & \multirow{7}{*}{$\begin{array}{c}\text { Gua } \\
\text { ngdo } \\
\text { ng }\end{array}$} & 2011 & 28.6 & 4890 & 583.60 & 7.93 & 6.8082 & 46.25 & 2.65 \\
\hline 19 & & 2012 & 28.4 & 6333 & 588.56 & 7.48 & 6.8328 & 43.22 & 2.61 \\
\hline 19 & & 2013 & 28.3 & 8268 & 591.33 & 7.52 & 6.8635 & 42.91 & 2.47 \\
\hline 19 & & 2014 & 31.5 & 8415 & 595.78 & 7.78 & 6.8952 & 41.07 & 2.42 \\
\hline 19 & & 2015 & 26.4 & 11660 & 602.72 & 7.68 & 6.9321 & 39.30 & 2.24 \\
\hline 19 & & 2016 & 25.0 & 13982 & 611.06 & 7.47 & 6.9616 & 36.89 & 1.89 \\
\hline 19 & & 2017 & 33.8 & 18693 & 620.50 & 7.47 & 6.9731 & 37.93 & 1.69 \\
\hline 20 & \multirow{7}{*}{$\begin{array}{l}\text { Gua } \\
\text { ngxi }\end{array}$} & 2011 & 34.9 & 268 & 195.99 & 7.98 & 6.1754 & 58.47 & 0.64 \\
\hline 20 & & 2012 & 36.7 & 374 & 197.55 & 7.41 & 6.2253 & 56.68 & 0.42 \\
\hline 20 & & 2013 & 35.1 & 594 & 199.11 & 7.62 & 6.2479 & 57.65 & 0.35 \\
\hline 20 & & 2014 & 35.8 & 791 & 200.59 & 8.07 & 6.3133 & 51.02 & 0.45 \\
\hline 20 & & 2015 & 30.7 & 1016 & 202.36 & 8.02 & 6.3346 & 44.25 & 0.72 \\
\hline 20 & & 2016 & 27.7 & 1245 & 204.14 & 7.48 & 6.3507 & 46.13 & 0.37 \\
\hline 20 & & 2017 & 37.4 & 1219 & 206.12 & 7.55 & 6.3693 & 45.17 & 0.31 \\
\hline 21 & \multirow{7}{*}{$\begin{array}{l}\text { Hain } \\
\text { an }\end{array}$} & 2011 & 15.2 & 41 & 250.67 & 8.41 & 6.2069 & 36.39 & 3.99 \\
\hline 21 & & 2012 & 10.2 & 83 & 253.30 & 8.05 & 6.2725 & 39.40 & 3.71 \\
\hline 21 & & 2013 & 15.0 & 175 & 255.79 & 8.36 & 6.3333 & 41.89 & 3.60 \\
\hline 21 & & 2014 & 13.1 & 143 & 258.14 & 8.51 & 6.4612 & 39.97 & 3.36 \\
\hline 21 & & 2015 & 13.7 & 180 & 260.42 & 8.52 & 6.5037 & 39.51 & 3.35 \\
\hline 21 & & 2016 & 12.9 & 249 & 262.14 & 7.99 & 6.5303 & 36.15 & 3.46 \\
\hline 21 & & 2017 & 22.8 & 257 & 264.71 & 8.40 & 6.6171 & 37.34 & 3.46 \\
\hline 22 & & 2011 & 45.4 & 850 & 355.98 & 7.58 & 6.5125 & 58.41 & 3.70 \\
\hline
\end{tabular}




\begin{tabular}{|c|c|c|c|c|c|c|c|c|c|}
\hline 22 & \multirow{6}{*}{$\begin{array}{c}\text { Cho } \\
\text { ngqi } \\
\text { ng }\end{array}$} & 2012 & 45.7 & 1229 & 359.15 & 7.48 & 6.5794 & 51.97 & 1.92 \\
\hline 22 & & 2013 & 45.7 & 1382 & 362.20 & 6.81 & 6.6283 & 51.42 & 1.97 \\
\hline 22 & & 2014 & 41.9 & 1316 & 364.80 & 6.58 & 6.7606 & 50.67 & 1.78 \\
\hline 22 & & 2015 & 40.0 & 2080 & 367.98 & 6.72 & 6.7831 & 48.35 & 1.46 \\
\hline 22 & & 2016 & 37.2 & 2599 & 371.76 & 7.26 & 6.7926 & 44.04 & 1.03 \\
\hline 22 & & 2017 & 39.6 & 2439 & 375.05 & 6.98 & 6.8341 & 42.26 & 0.75 \\
\hline 23 & \multirow{7}{*}{$\begin{array}{c}\text { Sich } \\
\text { uan }\end{array}$} & 2011 & 23.8 & 1486 & 165.98 & 7.20 & 6.2691 & 41.54 & 2.91 \\
\hline 23 & & 2012 & 22.8 & 1914 & 166.52 & 7.02 & 6.3015 & 41.22 & 2.59 \\
\hline 23 & & 2013 & 23.5 & 3032 & 167.15 & 6.84 & 6.3405 & 43.42 & 2.40 \\
\hline 23 & & 2014 & 21.4 & 2660 & 167.84 & 6.66 & 6.4267 & 39.69 & 2.19 \\
\hline 23 & & 2015 & 19.3 & 3665 & 169.16 & 6.61 & 6.5379 & 33.36 & 2.05 \\
\hline 23 & & 2016 & 18.9 & 4712 & 170.35 & 6.90 & 6.6264 & 31.11 & 1.60 \\
\hline 23 & & 2017 & 23.5 & 4874 & 171.18 & 6.81 & 6.6116 & 26.88 & 1.44 \\
\hline 24 & \multirow{7}{*}{$\begin{array}{c}\text { Guiz } \\
\text { hou }\end{array}$} & 2011 & 33.3 & 235 & 197.09 & 7.36 & 6.6384 & 95.20 & 0.59 \\
\hline 24 & & 2012 & 34.1 & 319 & 197.96 & 7.10 & 6.6079 & 96.37 & 0.46 \\
\hline 24 & & 2013 & 30.6 & 493 & 198.99 & 7.49 & 6.5810 & 104.86 & 0.45 \\
\hline 24 & & 2014 & 30.6 & 549 & 199.32 & 7.63 & 6.5074 & 96.51 & 0.31 \\
\hline 24 & & 2015 & 28.3 & 791 & 200.57 & 7.49 & 6.4593 & 92.15 & 0.25 \\
\hline 24 & & 2016 & 24.5 & 750 & 201.99 & 7.29 & 6.4510 & 95.29 & 0.54 \\
\hline 24 & & 2017 & 29.8 & 899 & 203.41 & 7.42 & 6.5142 & 91.38 & 0.41 \\
\hline 25 & \multirow{7}{*}{$\begin{array}{l}\text { Yun } \\
\text { nan }\end{array}$} & 2011 & 16.4 & 368 & 117.53 & 8.25 & 6.3750 & 72.36 & 1.18 \\
\hline 25 & & 2012 & 13.9 & 470 & 118.25 & 8.41 & 6.3591 & 67.43 & 1.25 \\
\hline 25 & & 2013 & 16.7 & 641 & 118.95 & 7.98 & 6.3701 & 69.38 & 1.21 \\
\hline 25 & & 2014 & 13.5 & 774 & 119.64 & 7.50 & 6.4254 & 59.27 & 1.18 \\
\hline 25 & & 2015 & 13.1 & 950 & 120.36 & 7.19 & 6.4791 & 53.19 & 1.25 \\
\hline 25 & & 2016 & 13.0 & 1273 & 121.09 & 8.02 & 6.5258 & 50.01 & 0.35 \\
\hline 25 & & 2017 & 16.7 & 1427 & 121.85 & 7.76 & 6.5259 & 46.44 & 0.35 \\
\hline 26 & & 2011 & 42.0 & 938 & 181.68 & 7.46 & 6.4396 & 97.46 & 1.25 \\
\hline
\end{tabular}




\begin{tabular}{|c|c|c|c|c|c|c|c|c|c|}
\hline 26 & \multirow{6}{*}{$\begin{array}{c}\text { Shan } \\
\text { xi }\end{array}$} & 2012 & 39.2 & 1150 & 182.19 & 7.27 & 6.4478 & 106.04 & 1.31 \\
\hline 26 & & 2013 & 46.1 & 2011 & 182.70 & 6.89 & 6.4518 & 116.12 & 1.43 \\
\hline 26 & & 2014 & 39.9 & 2093 & 183.26 & 7.14 & 6.5145 & 116.96 & 1.47 \\
\hline 26 & & 2015 & 40.6 & 2326 & 184.13 & 7.01 & 6.5833 & 112.02 & 1.61 \\
\hline 26 & & 2016 & 37.7 & 2524 & 185.10 & 7.42 & 6.6233 & 115.93 & 1.75 \\
\hline 26 & & 2017 & 41.6 & 2508 & 186.17 & 7.19 & 6.6019 & 114.35 & 1.85 \\
\hline 27 & \multirow{7}{*}{$\begin{array}{c}\text { Gans } \\
\mathrm{u}\end{array}$} & 2011 & 42.4 & 209 & 56.48 & 6.36 & 6.3987 & 69.31 & 0.09 \\
\hline 27 & & 2012 & 40.6 & 321 & 56.77 & 6.44 & 6.4105 & 66.85 & 0.07 \\
\hline 27 & & 2013 & 51.1 & 392 & 56.88 & 5.98 & 6.4219 & 64.12 & 0.07 \\
\hline 27 & & 2014 & 50.6 & 397 & 57.07 & 6.46 & 6.5127 & 63.78 & 0.09 \\
\hline 27 & & 2015 & 43.9 & 474 & 57.26 & 6.75 & 6.6066 & 62.26 & 0.10 \\
\hline 27 & & 2016 & 37.9 & 640 & 57.48 & 6.63 & 6.6718 & 62.11 & 0.11 \\
\hline 27 & & 2017 & 48.7 & 802 & 57.84 & 6.54 & 6.6466 & 60.27 & 0.04 \\
\hline 28 & \multirow{7}{*}{$\begin{array}{l}\text { Qing } \\
\text { hai }\end{array}$} & 2011 & 38.5 & 20 & 8.15 & 6.30 & 6.4124 & 33.78 & 0.80 \\
\hline 28 & & 2012 & 36.7 & 41 & 8.22 & 5.61 & 6.4225 & 37.68 & 0.85 \\
\hline 28 & & 2013 & 41.6 & 55 & 8.29 & 5.31 & 6.4009 & 39.30 & 0.34 \\
\hline 28 & & 2014 & 52.6 & 38 & 8.37 & 5.38 & 6.4938 & 32.50 & 0.17 \\
\hline 28 & & 2015 & 35.3 & 124 & 8.44 & 5.98 & 6.6081 & 26.06 & 0.17 \\
\hline 28 & & 2016 & 34.7 & 145 & 8.51 & 6.64 & 6.6364 & 34.10 & 0.04 \\
\hline 28 & & 2017 & 48.4 & 155 & 8.59 & 5.91 & 6.6003 & 29.70 & 0.05 \\
\hline 29 & \multirow{7}{*}{$\begin{array}{c}\text { Ning } \\
\text { xia }\end{array}$} & 2011 & 37.8 & 69 & 96.89 & 6.23 & 6.5927 & 131.51 & 0.68 \\
\hline 29 & & 2012 & 36.6 & 70 & 98.06 & 5.75 & 6.6219 & 126.11 & 0.65 \\
\hline 29 & & 2013 & 46.9 & 126 & 99.12 & 5.84 & 6.6165 & 127.49 & 0.39 \\
\hline 29 & & 2014 & 41.5 & 193 & 100.30 & 6.02 & 6.6722 & 127.91 & 0.23 \\
\hline 29 & & 2015 & 37.2 & 202 & 101.21 & 6.24 & 6.7255 & 117.72 & 0.45 \\
\hline 29 & & 2016 & 34.5 & 304 & 102.27 & 6.53 & 6.7242 & 110.68 & 0.61 \\
\hline 29 & & 2017 & 39.6 & 385 & 103.33 & 6.17 & 6.7668 & 121.73 & 0.66 \\
\hline 30 & & 2011 & 51.3 & 194 & 13.27 & \#REF! & 6.1831 & 70.12 & 0.33 \\
\hline
\end{tabular}




\begin{tabular}{|c|c|c|c|c|c|c|c|c|c|}
\hline 30 & \multirow{6}{*}{$\begin{array}{c}\text { Xinji } \\
\text { ang }\end{array}$} & 2012 & 51.2 & 244 & 13.41 & 4.62 & 6.2073 & 72.62 & 0.35 \\
\hline 30 & & 2013 & 56.9 & 405 & 13.60 & 4.66 & 6.2339 & 74.44 & 0.35 \\
\hline 30 & & 2014 & 64.6 & 396 & 13.80 & 4.60 & 6.3358 & 76.99 & 0.28 \\
\hline 30 & & 2015 & 54.7 & 576 & 14.17 & 4.99 & 6.4219 & 79.23 & 0.30 \\
\hline 30 & & 2016 & 51.0 & 662 & 14.40 & 4.45 & 6.4198 & 83.19 & 0.28 \\
\hline 30 & & 2017 & 58.2 & 813 & 14.68 & 4.40 & 6.4248 & 83.66 & 0.12 \\
\hline
\end{tabular}

727 